\title{
Azole susceptibility and resistance in Condida dubliniensis
}

\author{
E. Pinjon ${ }^{1}$, G.P. Moran, D.C. Coleman and D.J. Sullivan \\ Microbiology Research Unit, Division of Oral Biosciences, School of Dental Science and Dublin Dental Hospital, University of Dublin, Trinity College, Dublin 2 , \\ Republic of Ireland
}

\begin{abstract}
Condida dubliniensis is a recently described species of pathogenic yeast that shares many phenotypic features with Candida albicans. It is primarily associated with oral colonization and infection in HIV-infected individuals. Isolates of $\boldsymbol{C}$. dubliniensis are generally susceptible to commonly used azole antifungal agents; however, resistance has been observed in clinical isolates and can be induced by in vitro exposure. Molecular mechanisms of azole resistance in $C$. dubliniensis include increased drug efflux, modifications of the target enzyme and alterations in the ergosterol biosynthetic pathway.
\end{abstract}

\section{Introduction}

Several species of the genus Candida form part of the normal oropharyngeal and gastrointestinal flora; however, they can become opportunistic pathogens and establish infections when host defences are impaired. Such infections range from superficial infections of the skin and mucous membranes to life-threatening invasive infections of the blood and/or organs. Having emerged as significant human pathogens during the past 2 decades, Candida species are frequently quoted as the fourth most common cause of nosocomial bloodstream infection in the U.S.A., with an associated mortality rate of $40-60 \%$. The emergence of Candida species as significant human pathogens has been part of a general increase in the number of infections caused by fungal pathogens during the last 20 years. This shift in the epidemiology of fungal infections has been correlated with the increase in the number of immunocompromised and immunosuppressed patients, as well as with an increase in the use of invasive medical procedures, in-dwelling central venous catheters and broad-spectrum antibiotics. Candida albicans is the most pathogenic Candida species and is the most common cause of Candida infections. However, over the last 2 decades, since the introduction and widespread use of the azole drugs fluconazole and itraconazole, other Candida species have emerged as significant pathogens of clinical importance [1]. This review focuses on one of these species, Candida dubliniensis, with particular emphasis on its resistance mechanisms to azole antifungal agents.

Key words: azole, condida dubliniensis, epidemiology, fluconazole, susceptibility, resistance mechanism.

Abbreviations used: $C d$, Condida dubliniensis; $C d r 1 p$, Condida drug resistance protein 1; Mdr1p, multidrug resistance protein 1; MIC, minimum inhibitory concentration.

${ }^{1}$ To whom correspondence should be addressed (email emmanuelle.pinjon@dental. tcd.ie).

\section{A recently described species: Candida dubliniensis}

In the early 1990s, several authors reported the recovery of atypical isolates of C. albicans from HIV-infected individuals [2,3]. Although these isolates shared many features characteristic of C. albicans, they exhibited a number of atypical properties. These atypical isolates possessed the ability to form germ tubes and abundant chlamydospores [4]. However, they grew poorly or not at all at $42^{\circ} \mathrm{C}$, unlike C. albicans isolates which grow well at this temperature. An extensive study of the phenotypic and genotypic characteristics of atypical isolates recovered from the oral cavities of HIV-infected patients in Ireland and Australia, together with a phylogenetic analysis of nucleotide sequences of the $\mathrm{V} 3$ region of the large rRNA subunit gene, demonstrated that the atypical isolates constituted a novel distinct taxon within the genus Candida for which the name C. dubliniensis was proposed [4].

\section{Epidemiology of C. dubliniensis}

Since its identification in 1995, numerous studies have reported the recovery of C. dubliniensis isolates from a wide range of anatomical sites and clinical settings all over the world [5-8]. Despite its phenotypic similarities with C. albicans, C. dubliniensis appears to be a rare constituent of the normal oral and vaginal microbial flora. In a study of an Irish population, only $3.5 \%$ of normal healthy individuals were found to carry C. dubliniensis in the oral cavity [9]. However, C. dubliniensis is commonly associated with oropharyngeal candidosis in HIV-infected and AIDS patients $[10,11]$. A high prevalence (15-30\%) of C. dubliniensis in the oral cavities of HIV-infected and AIDS patients has been reported in several studies $[9,11,12]$. In a study on the prevalence of C. dubliniensis in the oral cavity in an Irish population, $26 \%$ of HIV-infected and $32 \%$ of AIDS patients 
with symptoms of oral candidosis harboured C. dubliniensis, while, in asymptomatic patients, the levels were $18 \%$ and $25 \%$ respectively [9]. However, some studies have reported a significantly lower prevalence in HIV-infected and AIDS patients $[13,14]$, although the reasons for this disparity are unclear. A relatively high prevalence of $C$. dubliniensis in the oral cavities of patients with denture stomatitis [9], diabetes [15] and cystic fibrosis [16] has also been reported.

While C. dubliniensis is most frequently isolated from the oral cavity, it has also been recovered from faecal, sputum, vaginal, urine and wound samples [17-22]. C. dubliniensis isolates have also been recovered from the blood of patients with invasive candidosis [23], particularly those with neutropenia following bone marrow or solid organ transplantation [19,24-26]. However, the incidence of C. dubliniensis in systemic infections is low, accounting for up to $2 \%$ of cases of candidaemia in the U.K. [18] and in the U.S.A. [25], which contrasts with the $65 \%$ of candidaemia cases accounted for by $C$. albicans. This disparity could be explained by the higher prevalence of C. albicans in the normal flora, but it also suggests that $C$. dubliniensis is less pathogenic than C. albicans.

The reasons for the emergence of C. dubliniensis during the last 15 years are not clear. It has been suggested that, since C. dubliniensis was initially isolated from the oral cavities of HIV-infected patients with recurrent oral candidosis receiving azole antifungal drug therapy, the emergence of this species may have been due to positive selection as a result of the introduction of fluconazole for the prophylaxis and treatment of oral candidosis in the early 1990s.

\section{Azole susceptibility in C. dubliniensis}

Azole derivatives target the synthesis of ergosterol, the predominant sterol of the fungal cell membrane, and are currently the most widely used class of antifungal agents in the treatment of Candida infections. The vast majority of C. dubliniensis clinical isolates are susceptible to azole antifungal drugs. In a recent study, $94.6 \%$ of the 111 C. dubliniensis isolates tested were found to be susceptible to fluconazole [MIC (minimum inhibitory concentration) range $0.125-4 \mu \mathrm{g} / \mathrm{ml}$ ], while $89.6 \%$ of 58 isolates were found to be susceptible to itraconazole (MIC range $0.03-0.125 \mu \mathrm{g} / \mathrm{ml}$ ) [27]. Other recent studies reported similar findings $[28,29]$.

While most isolates of C. dubliniensis are susceptible to fluconazole, a number of isolates exhibiting either decreased susceptibility $(8 \mu \mathrm{g} / \mathrm{ml} \leqslant \mathrm{MIC} \leqslant 32 \mu \mathrm{g} / \mathrm{ml})$ or resistance $(\mathrm{MIC} \geqslant 64 \mu \mathrm{g} / \mathrm{ml})$ to fluconazole have been described $[12,20,21,28-32]$. These isolates were mostly recovered from HIV-infected patients receiving fluconazole therapy. Furthermore, Moran et al. [30] showed that fluconazoleresistant derivatives could be generated from susceptible isolates following sequential exposure to fluconazole in vitro, thus indicating that $C$. dubliniensis has the ability to rapidly develop resistance to this drug. In vitro exposure to fluconazole has also been shown to result in increased adherence of C. dubliniensis to epithelial cells which correlated with increased proteinase secretion levels, whereas the adherence of C. albicans was decreased under the same conditions [33]. It is thus possible that treatment with fluconazole could provide a selective advantage favouring the growth of $C$. dubliniensis over C. albicans isolates in the oral cavity. This could explain the high recovery rate of $C$. dubliniensis isolates from HIVinfected patients receiving fluconazole treatment. In addition, Odds et al. [20] have shown that the geometric mean MICs of C. dubliniensis for azole drugs are significantly higher than those of C. albicans.

Oral populations of Candida are dynamic and, in a longitudinal study, Martinez et al. [34] described the replacement of C. albicans with C. dubliniensis in HIV-infected patients with oral candidosis treated with fluconazole. The switch to C. dubliniensis occurred in patients initially infected with C. albicans strains that failed to develop fluconazole resistance. This is the only study so far to have provided evidence that $C$. dubliniensis can replace C. albicans following azole therapy and, although the antifungal pressure owing to prolonged fluconazole treatment may have played a role in the selection of the C. dubliniensis isolates, other factors may have been involved as the majority of $C$. dubliniensis isolates recovered at the end of the study did not exhibit decreased susceptibility to azoles [34].

Resistance to itraconazole has been described in clinical isolates of C. dubliniensis [21], and it can be induced by in vitro exposure to the drug [27].

\section{Mechanisms of azole resistance in C. dubliniensis}

Azole drugs target an enzyme of the ergosterol biosynthetic pathway known as lanosterol $14 \alpha$-demethylase, which is encoded by the ERG11 gene. Exposure of fungal cells to azoles causes depletion of ergosterol and accumulation of $14 \alpha$ methylated sterols, such as lanosterol and $14 \alpha$-methyl-3,6diol, which disrupt the structure of the membrane, alter its fluidity and the activity of membrane-bound enzymes. Several molecular mechanisms by which Candida cells can develop resistance to azole antifungal agents have been described: cells can fail to accumulate these agents owing to increased drug efflux, mutations can alter the affinity of the target enzyme for these agents, the cellular content of the target enzyme can be elevated, and other enzymes of the ergosterol biosynthetic pathway, such as the sterol C5,6-desaturase, can be inactivated by mutation (Figure 1).

Failure to accumulate azole antifungals has been shown to be a major factor involved in azole resistance in clinical C. albicans isolates, and numerous studies have reported the association of azole drug resistance with the up-regulation of genes encoding multidrug efflux transporters [35-37]. Two types of efflux transporters have been shown to contribute to azole resistance in Candida: the ABC (ATP-binding cassette) transporters $\mathrm{Cdr} 1 \mathrm{p}$ (Candida drug resistance protein 1) and Cdr2p, encoded by the $C D R 1$ and $C D R 2$ genes respectively, and the major facilitator protein $\mathrm{Mdr} 1 \mathrm{p}$ (multidrug resistance protein 1), encoded by the $M D R 1$ gene. While Cdr1p 
Figure 1 | Schematic representation of resistance mechanisms to azole antifungal agents in Candida

(1) Decreased accumulation of drug due to up-regulation of ABC (ATP-binding cassette) and major facilitator multidrug transporter genes. (2) Decreased affinity to azoles of the target enzyme Erg11p. (3) Increased cellular content of Erg11p. (4) Alteration of the ergosterol biosynthetic pathway by inactivation of Erg3p (sterol c5,6-desaturase).
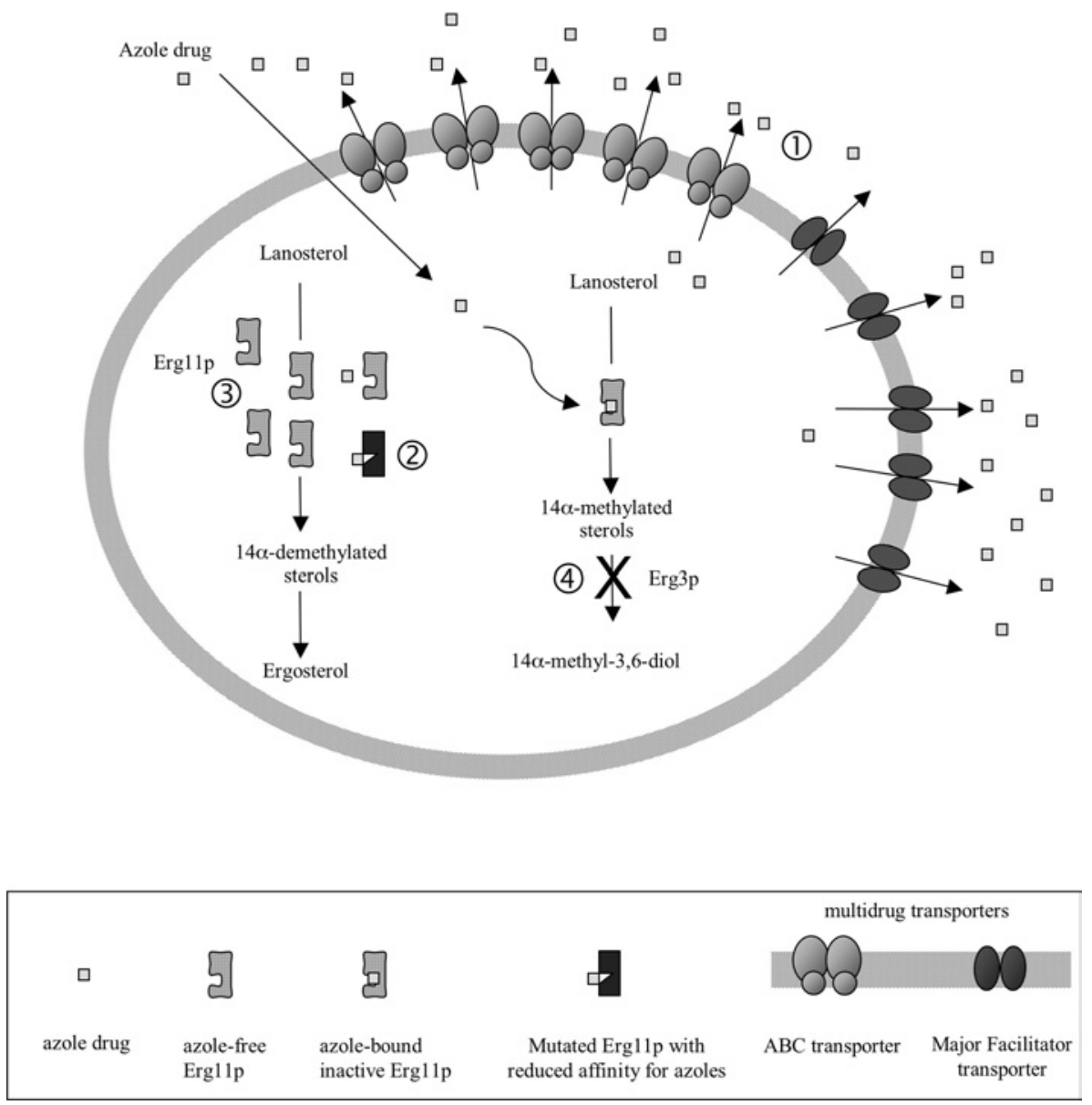

and Cdr2p can transport a broad range of azole drugs, including itraconazole and ketoconazole, Mdr1p can only transport fluconazole. Homologues of the genes encoding the $C$. albicans multidrug transporters have been identified in C. dubliniensis (termed CdMDR1, CdCDR1 and CdCDR2 respectively), and their up-regulation has been associated with azole resistance [31]. Overexpression of $C d M D R 1$ has been shown to be involved in mediating a reduced accumulation of drug in fluconazole-resistant clinical isolates and in-vitro-generated derivatives [38]. Furthermore, the role of $C d M D R 1$ in fluconazole resistance has been confirmed by the disruption of both alleles of the gene in a fluconazoleresistant clinical isolate overexpressing CdMDR1 [39].

Up-regulation of $C d C D R 1$ has been observed in fluconazole-resistant clinical isolates of C. dubliniensis and in-vitrogenerated derivatives [31,38]. However, Moran et al. [40] have shown that, while CdCdr1p is important for mediating reduced susceptibility to itraconazole and ketoconazole, it is not required for fluconazole resistance in isolates that exhibit increased $C d M D R 1$ expression. In contrast, in
C. albicans, resistance to fluconazole is mainly associated with overexpression of $C D R 1$. In a study that investigated the reasons for the differential regulation of $C D R 1$ expression in C. albicans and C. dubliniensis, Moran et al. [40] reported the high prevalence amongst C. dubliniensis isolates of a nonsense mutation in the $C d C D R 1$ gene. $C d C D R 1$ genes that harbour the nonsense mutation encode a non-functional CdCdr1p protein and correction of the mutation by sitedirected mutagenesis has been shown to restore function [40]. All isolates that harbour the nonsense mutation belong to C. dubliniensis genotype 1, a group of very closely related isolates that have mainly been recovered from HIV-infected individuals, many of whom have received fluconazole treatment [17]. In these isolates, cross-resistance to other azole drugs has not been described, and this observation is consistent with up-regulation of $C d M D R 1$ as the primary mechanism of fluconazole resistance, since this transporter can only transport fluconazole and not any other azoles. In contrast, in a recent study of genotype 3 C. dubliniensis isolates, decreased susceptibility to fluconazole was associated 
with up-regulation of $C d C D R 1$ and $C d C D R 2$, while expression of $C d M D R 1$ was not detected [32]. In these isolates, decreased susceptibility to fluconazole was associated with decreased susceptibility to other azoles. While this was the first report of $C d C D R 2$ overexpression in clinical isolates of $C$. dubliniensis, the exact contribution of $C d C D R 2$ upregulation to the phenotype of decreased azole susceptibility is unclear because of the concomitant up-regulation of CdCDR1 [32].

In $C$. albicans, mutations that affect the affinity of the target enzyme Erg11p for azole antifungal drugs have been well documented as a drug-resistance mechanism [41-46]. In C. dubliniensis, Perea et al. [31] have described mutations in the CdERG11 gene which were associated with fluconazole resistance. Two of the mutations described by Perea et al. [31] (F126L and G464S) are identical with mutations that have been shown previously to be involved in fluconazole resistance in C. albicans. The other mutations identified by Perea et al. [31] have not yet been conclusively shown to be involved in azole resistance.

Although up-regulation of ERG11 has been associated with azole resistance in several clinical isolates of $C$. albicans $[47,48]$, the contribution of ERG11 overexpression to azole resistance has been difficult to assess because it has always been found in combination with other alterations that are associated with azole resistance, such as decreased accumulation of drug or the presence of mutations in Erg11p. Similarly, in C. dubliniensis, up-regulation of $C d E R G 11$ has been observed, but always in conjunction with other resistance mechanisms, and thus the relevance of increased levels of the target enzyme in mediating azole resistance in C. dubliniensis is not known [27,31].

In C. albicans, resistance to azole drugs has also been associated with modifications of the ergosterol biosynthetic pathway, such as defects in the sterol C5,6-desaturation step that avoid the accumulation of the toxic $14 \alpha$-methyl-3,6diol metabolite and circumvent azole-mediated growth arrest $[49,50]$. Loss of function mutations in the C. dubliniensis homologue of the gene encoding this enzyme ( $C d E R G 3)$ have been shown to be associated with the development of azole resistance in $C$. dubliniensis following sequential exposure to itraconazole in vitro [27]. Although increased expression of $C d C D R 1$ and $C d E R G 11$ was also observed in the azoleresistant derivatives generated by itraconazole exposure, this was thought to be a consequence of alterations in membrane composition owing to the defective C5,6-desaturation step of the ergosterol biosynthetic pathway, rather than the cause of azole resistance [27]. Thus the study highlighted the fact that, if not thoroughly investigated, azole resistance can be wrongly attributed to the apparent overexpression of multidrug resistance genes and the target enzyme. Sterol C5,6desaturase loss-of-function mutations provide a mechanism which is often overlooked and its contribution to clinical azole resistance remains to be investigated further, not only in C. dubliniensis, but in all Candida species.

In C. albicans, azole resistance is often multifactorial, sometimes involving the up-regulation of more than one multidrug transporter in conjunction with point mutations in Erg11p and up-regulation of the ERG11 gene [47,48]. Similarly, in C. dubliniensis, the development of azole resistance appears to be a complex phenomenon that can involve multiple molecular mechanisms working in combination [31].

In summary, the molecular mechanisms of azole resistance in C. dubliniensis are similar to those previously described in C. albicans, although genotype-specific combinations of mechanisms have been described.

We acknowledge the support of the Irish Health Research Board (grants 04-97 and RP/2002/6) and of the Dublin Dental School and Hospital.

\section{References}

1 Moran, G.P., Sullivan, D.J. and Coleman, D.C. (2002) in Condida and candidiasis (Calderone, R.A., ed.), pp. 37-53, ASM Press, Washington, DC

2 McCullough, M., Ross, B. and Reade, P. (1995) J. Clin. Microbiol. 33 696-700

3 Sullivan, D., Bennett, D., Henman, M., Harwood, P., Flint, S., Mulcahy, F., Shanley, D. and Coleman, D. (1993) J. Clin. Microbiol. 31, 2124-2133

4 Sullivan, D.J., Westerneng, T.J., Haynes, K.A., Bennett, D.E. and Coleman, D.C. (1995) Microbiology 141, 1507-1521

5 Sullivan, D., Haynes, K., Bille, J., Boerlin, P., Rodero, L., Lloyd, S., Henman, M. and Coleman, D. (1997) J. Clin. Microbiol. 35, 960-964

6 Kamei, K., McCullough, M.J. and Stevens, D.A. (2000) Med. Mycol. 38 81-83

7 Fisher, J.M., Basson, N.J. and van Zyl, A. (2001) South African Dent. J. 56, 599-601

8 Silva, V., Cabrera, M., Diaz, M.C., Abarca, C. and Hermosilla, G. (2003) Rev. Iberoam. Micol. 20, 46-51

9 Ponton, J., Ruchel, R., Clemons, K.V., Coleman, D.C., Grillot, R., Guarro, J., Aldebert, D., Ambroise-Thomas, P., Cano, J., Carrillo-Munoz, A.J. et al. (2000) Med. Mycol. 38 (suppl. 1), 225-236

10 Coleman, D.C., Sullivan, D.J., Bennett, D.E., Moran, G.P., Barry, H.J. and Shanley, D.B. (1997) AIDS 11, 557-567

11 Schoofs, A.G., Odds, F.C., Colebunders, R., leven, M. and Goossens, H. (1998) Mycoses 41, 203-211

12 Kirkpatrick, W.R., Revankar, S.G., McAtee, R.K., Lopez-Ribot, J.L., Fothergill, A.W., McCarthy, D.I., Sanche, S.E., Cantu, R.A., Rinaldi, M.G. and Patterson, T.F. (1998) J. Clin. Microbiol. 36, 3007-3012

13 Vargas, K.G. and Joly, S. (2002) J. Clin. Microbiol. 40, 341-350

14 Blignaut, E., Pujol, C., Joly, S., Soll, D.R. and Lockhart, S. (2003) J. Clin. Microbiol. 41, 1838-1842

15 Willis, A.M., Coulter, W.A., Sullivan, D.J., Coleman, D.C., Hayes, J.R., Bell, P.M. and Lamey, P.J. (2000) J. Oral Pathol. Med. 29, 86-90

16 Peltroche-Llacsahuanga, H., Dohmen, H. and Haase, G. (2002) Mycoses 45, 15-18

17 Gee, S.F., Joly, S., Soll, D.R., Meis, J.F., Verweij, P.E., Polacheck, I., Sullivan, D.J. and Coleman, D.C. (2002) J. Clin. Microbiol. 40, 556-574

18 Kibbler, C.C., Ainscough, S., Barnes, R.A., Grandsen, W.R., Holliman, R.E., Johnson, E.M., Perry, J.D., Sullivan, D.J. and Wilson, J.A. (2003) J. Hosp. Infect. 54, 18-24

19 Meis, J.F., Ruhnke, M., De Pauw, B.E., Odds, F.C., Siegert, W. and Verweij, P.E. (1999) Emerg. Infect. Dis. 5, 150-153

20 Odds, F.C., Van Nuffel, L. and Dams, G. (1998) J. Clin. Microbiol. 36, 2869-2873

21 Fotedar, R. and Al-Hedaithy, S.S. (2003) J. Clin. Microbiol. 41, 1907-1911

22 Al Mosaid, A., Sullivan, D.J., Polacheck, I., Shaheen, F.A., Soliman, 0., Al Hedaithy, S., Al Thawad, S., Kabadaya, M. and Coleman, D.C. (2005) J. Clin. Microbiol. 43, 4026-4036

23 Marriott, D., Laxton, M. and Harkness, J. (2001) Emerg. Infect. Dis. 7, 479

24 Gottlieb, G.S., Limaye, A.P., Chen, Y.C. and Van Voorhis, W.C. (2001) Med. Mycol. 39, 483-485

25 Sebti, A., Kiehn, T.E., Perlin, D., Chaturvedi, V., Wong, M., Doney, A. Park, S. and Sepkowitz, K.A. (2001) Clin. Infect. Dis. 32, 1034-1038

26 Brandt, M.E., Harrison, L.H., Pass, M., Sofair, A.N., Huie, S., Li, R.K., Morrison, C.J., Warnock, D.W. and Hajjeh, R.A. (2000) Emerg. Infect. Dis. 6, 46-49 
27 Pinjon, E., Moran, G.P., Jackson, C.J., Kelly, S.L., Sanglard, D., Coleman, D.C. and Sullivan, D.J. (2003) Antimicrob. Agents Chemother. 47, 2424-2437

28 Pfaller, M.A., Diekema, D.J., Messer, S.A., Hollis, R.J. and Jones, R.N. (2003) Antimicrob. Agents Chemother. 47, 1068-1071

29 Pfaller, M.A., Diekema, D.J., Messer, S.A., Boyken, L., Hollis, R.J. and Jones, R.N. (2004) Diagn. Microbiol. Infect. Dis. 48, 101-105

30 Moran, G.P., Sullivan, D.J., Henman, M.C., McCreary, C.E., Harrington, B.J., Shanley, D.B. and Coleman, D.C. (1997) Antimicrob. Agents Chemother. 41, 617-623

31 Perea, S., Lopez-Ribot, J.L., Wickes, B.L., Kirkpatrick, W.R., Dib, O.P. Bachmann, S.P., Keller, S.M., Martinez, M. and Patterson, T.F. (2002) Antimicrob. Agents Chemother. 46, 1695-1703

32 Pinjon, E., Jackson, C.J., Kelly, S.L., Sanglard, D., Moran, G., Coleman, D.C. and Sullivan, D.J. (2005) Antimicrob. Agents Chemother. 49, 1312-1318

33 Borg-Von Zepelin, M., Niederhaus, T., Gross, U., Seibold, M., Monod, M. and Tintelnot, K. (2002) AIDS 16, 1237-1244

34 Martinez, M., Lopez-Ribot, J.L., Kirkpatrick, W.R., Coco, B.J., Bachmann, S.P. and Patterson, T.F. (2002) J. Clin. Microbiol. 40, 3135-3139

35 Albertson, G.D., Niimi, M., Cannon, R.D. and Jenkinson, H.F. (1996) Antimicrob. Agents Chemother. 40, 2835-2841

36 Sanglard, D., Kuchler, K., Ischer, F., Pagani, J.L., Monod, M. and Bille, J. (1995) Antimicrob. Agents Chemother. 39, 2378-2386

37 Sanglard, D., Ischer, F., Monod, M. and Bille, J. (1997) Microbiology 143 405-416

38 Moran, G.P., Sanglard, D., Donnelly, S.M., Shanley, D.B., Sullivan, D.J. and Coleman, D.C. (1998) Antimicrob. Agents Chemother. 42 1819-1830
39 Wirsching, S., Moran, G.P., Sullivan, D.J., Coleman, D.C. and Morschhauser, J. (2001) Antimicrob. Agents Chemother. 45, 3416-3421

40 Moran, G., Sullivan, D., Morschhauser, J. and Coleman, D. (2002) Antimicrob. Agents Chemother. 46, 2829-2841

41 Favre, B., Didmon, M. and Ryder, N.S. (1999) Microbiology 145 2715-2725

42 Kelly, S.L., Lamb, D.C. and Kelly, D.E. (1999) FEMS Microbiol. Lett. 180, 171-175

43 Kelly, S.L., Lamb, D.C., Loeffler, J., Einsele, H. and Kelly, D.E. (1999) Biochem. Biophys. Res. Commun. 262, 174-179

44 Lamb, D.C., Kelly, D.E., White, T.C. and Kelly, S.L. (2000) Antimicrob. Agents Chemother. 44, 63-67

45 Marichal, P., Koymans, L., Willemsens, S., Bellens, D., Verhasselt, P. Luyten, W., Borgers, M., Ramaekers, F.C., Odds, F.C. and Bossche, H.V. (1999) Microbiology 145, 2701-2713

46 Sanglard, D., Ischer, F., Koymans, L. and Bille, J. (1998) Antimicrob. Agents Chemother. 42, 241-253

47 White, T.C. (1997) Antimicrob. Agents Chemother. 41, 1482-1487

48 Perea, S., Lopez-Ribot, J.L., Kirkpatrick, W.R., McAtee, R.K., Santillan, R.A., Martinez, M., Calabrese, D., Sanglard, D. and Patterson, T.F. (2001) Antimicrob. Agents Chemother. 45, 2676-2684

49 Kelly, S.L., Lamb, D.C., Corran, A.J., Baldwin, B.C. and Kelly, D.E. (1995) Biochem. Biophys. Res. Commun. 207, 910-915

50 Miyazaki, Y., Geber, A., Miyazaki, H., Falconer, D., Parkinson, T. Hitchcock, C., Grimberg, B., Nyswaner, K. and Bennett, J.E. (1999) Gene 236, 43-51

Received 3 August 2005 